\title{
One Size Fits None: Tailoring Messages to Communicate Environmental Threats
}

\author{
Madelyn Pardon, ${ }^{1}$ James Cook University, Australia \\ Anne Swinbourne, James Cook University, Australia \\ Connar McShane, James Cook University, Australia
}

\begin{abstract}
This research aimed to understand peoples' perceptions of environmental threats to inform threat message construction and branch away from the previous "one size fits all" approach to environmental campaigns. The study used a health decision making model (Extended Parallel Process Model) to cluster individuals based on common cognitive characteristics. The research focused on the context of water security in the drought declared region of Townsville, North Queensland (Australia), where water use was monitored and restricted. A sample of 363 participants was recruited from this region. Participants completed an online survey which asked questions relating to water usage behaviours, perceptions relating to how the water restrictions were communicated, as well as the concerns regarding water security at the time and in the future. Three cluster groups were constructed based on EPPM variables (perceived self-efficacy, perceived response-efficacy, and perceived threat). Each group was significantly different in terms of levels of water-saving behaviour. This research informs a more targeted approach to the communication of environmental threats, such a drought, with the aim of increasing the sustainability of the natural resource.
\end{abstract}

Keywords: Water Sustainability, Extended Parallel Process Model, EPPM, Environmental Behaviour, Clusters

\section{Communicating Threat Information}

$\mathrm{F}$ ear appeals are arguably one of the most widely employed social marketing techniques used to communicate threat information. These campaigns use persuasive communication strategies to arouse an unpleasant emotional state in order to promote precautionary motivation and self-protective behaviours (Rogers 1983; Ruiter, Abraham, and Kok 2001). Fear appeals are commonly used in health behaviour promotion, with one of the most recent examples in Australia being the graphic anti-tobacco campaigns displayed on cigarette packets. The use of fear appeals to produce behaviour change has been adopted in additional contexts, such as environmental awareness. This adoption has had mixed success in terms of actual behaviour change due to the atheoretical approach to fear communication with an emphasis on installing high emotions of fear in viewers (Beattie, Sale, and McGuire 2011; Lorenzoni, Jones, and Turnpenny 2007; Moser and Dilling 2004; O’Neill and Nicholson-Cole 2009). As a result, consideration of older and successful behaviour prediction models, such as the Extended Parallel Process Model (EPPM) (Witte 1992), has been used to explain the inconsistent and unjustified outcomes in fear appeal research.

The EPPM is said to offer a more precise explanation of the processing of fear appeals than its predecessors, the Protection Motivation Theory (Rogers 1975) and the Parallel Process Model (Leventhal 1970). This is achieved by emphasising the relationship between threat and efficacy and re-incorporating fear as the central variable (Witte 1992). The EPPM makes predictions about the type of response individuals intend to make, as highlighted in Figure 1 below, depending on the interaction between the individual's perceived threat, perceived self-efficacy and perceived response-efficacy levels.

Within the model, threat is classified as something perceived as being of danger or harm to an individual (Witte 1992). The threat component of the EPPM is comprised of two elements, these being an individual's perceived susceptibility to a risk (for example, if the risk is in close

\footnotetext{
${ }^{1}$ Corresponding Author: Madelyn Pardon, 1 James Cook Drive, Douglas, Department of Psychology, James Cook University, Townsville, Queensland, 4814, Australia. email: madelyn.pardon@my.jcu.edu.au
} 
proximity [Hart and Feldman 2014]) and the perceived severity of the risk (for example, how much harm the risk can cause [Hart and Feldman 2014; Witte 1992]). When no threat is perceived the model predicts that an individual will not intend to make a behavioural response, as shown by "no response" in Figure 1. When threat is perceived, an individual's level of perceived efficacy is assumed to have an effect on the type of action an individual will intend to take. Efficacy itself is hypothesised to consist of two factors, these being perceived self-efficacy (whether an individual feels they can act), and perceived response-efficacy (belief in the effectiveness of the action) (Witte 1992). The type of action individuals take depends on the degree to which they perceive they have the ability to avert the threat.

A fear control response is hypothesised to be elicited when an individual has perceived the message as threatening and experiences the emotion of fear, while perceiving they have little or no efficacy to prevent the threat. An individual acts in such a way that they do not physically avert the perceived threat (Witte 1992). Alternatively, a danger control response is hypothesised to occur when an individual has perceived the message as threatening and believes they are able to take effective action to avert the threat. These actions often act in accordance to the message recommendations and attempt to directly reduce the threat (Witte 1992). Figure 1 below illustrates the EPPM and the predicted behavioural responses.

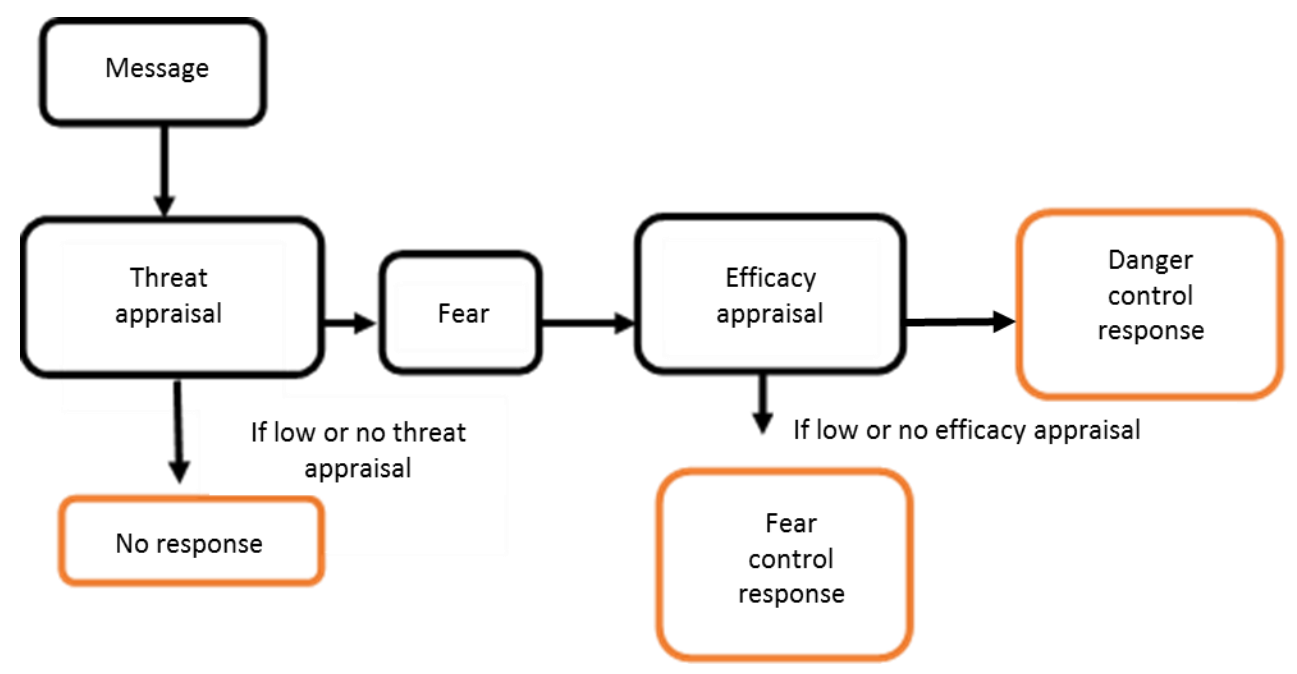

Figure 1: The Extended Parallel Process Model Source: Witte 1992

\section{The EPPM and Environmental Sustainability}

Currently, it could be argued that the communication of the majority of environmental messages is limited to one message being distributed to an entire population, often resulting in different interpretations and therefore diverse responses in terms of behaviour. One possible solution to overcome this challenge is market segmentation, which is claimed to engage more individuals in the desired response.

Although traditionally applied to health behaviours, the EPPM may be considered useful for understanding how environmental messages in the media inhibit or encourage public engagement and action towards an environmental issue. Research applying the EPPM in an environmental context is limited; however, the factors within the model have been shown to be successful and recommended by researchers in the prediction of environmental behaviour in response to environmental threat campaigns. Such research also emphasises the use of the combination of 
these factors for ultimate success (Hart and Feldman 2014; Perrault and Clark 2018; Xue et al. 2016; Li 2014).

Although the danger control process, as highlighted in Figure 1, of the EPPM predicts that a high level of perceived threat and efficacy increases individual's response in the face of fear, determinants of threat and efficacy are different for all individuals. Beliefs, values, and attitudes all play a role in an individual's threat perception of an issue. Additionally, it is also well known that a variety of others factors (for example, age, gender, household size, etc.) can have an impact on behaviour, particularly water usage behaviour (Randolf and Troy 2008; Gilg and Barr 2006). There is a growing body of research recognising that individuals can be clustered into groups based on their cognitive characteristics (Campo et al. 2012; Hine et al. 2014; Maibach et al. 2011; Rimal et al. 2009). This allows policy makers, advertisers, and the like to develop a set of cost-effective strategies to target information to a specific group of like-minded individuals and encourage particular perceptions, attitudes or even behaviours. The EPPM factors of perceived threat and perceived efficacy and their ability to predict behaviour when manipulated may provide an appropriate and simplistic foundation for the construction of messages to distribute to a community under direct environmental threat. These factors give an understanding of an individual's standing in terms of their behavioural compliance and therefore provide a basis to construct messages to alter these baseline perceptions. Therefore, separating individuals into groups based on similar standings on these variables will assist even further in the development of such communication strategies.

\section{Case Study: The City of Townsville}

Townsville, located in North Queensland (Australia), had been under environmental threat, in terms of a lack of water supply, for almost four years. Water restrictions were first enforced midAugust in 2015. The town's main water supply, the Ross River Dam, dropped to 14 percent capacity, with 10 percent being the point at which the restrictions were threatening to increase. At the time, approximately 70 percent of the total household water usage in Townsville was used on lawns and gardens. At their highest, the city experienced Level 3 water restrictions (outlined below), which were enforced by the Townsville City Council to minimise this particular use of water in the community. Failure to comply with these restrictions could have led to financial penalties for community members.

- No sprinkler and irrigation systems

- Handheld watering (only 6 a.m. to 7 a.m. and 6 p.m. to 7 p.m.) on an odds and evens watering system

- Buckets, watering cans, and drip irrigation systems can be used at any time

- Switch off all automatic watering systems

- Use a broom to clean hard surfaces (not a hose)

- Use a bucket of water efficient car wash to clean vehicles and boats

Note: Restrictions and water use policy vary between Local and State Governments in Australia.

With no sign of mass rainfall during this period and the apparent community inaction regarding water conservation, this established the interest to focus on individual-level behaviour in this context. Therefore the first aim of the current study was to explore how individuals perceived the water issue in the Townsville region in terms of perceived threat, perceived selfefficacy and perceived response-efficacy, to gather baseline cognitive characteristics. The study then aimed to cluster participants into groups based on the similarities between these cognitive characteristics (i.e., the ratings of perceived threat, perceived self-efficacy, and perceived response-efficacy), and determine if the behaviours of these different groups were in line with predictions of the EPPM. Secondly, the defining characteristics of each cluster were explored to determine which variables could be used to inform message construction. 


\section{Method}

\section{Participants}

A sample of 363 participants was recruited via online social media networks (Twitter and Facebook), university networks, and community networks (via local radio stations) from the Townsville region in North Queensland, Australia. Participants included 118 males and 243 females (two not indicating gender), ranging in age from 17 to 78 years $(M=42.57, S D=15.77)$. A total of 256 participants $(70.50 \%)$ indicated they were homeowners. The sample also indicated that they had lived in Townsville for an average of nineteen years $(M=19.10, S D=15.11)$.

\section{Measures}

All participants completed an online survey posted on the Qualtrics ${ }^{2}$ platform. The survey contained a total of 115 questions and was active from September 27th, 2017, until February 20th, 2018. Ethical approval for this study was obtained through the James Cook University (Townsville, Australia) Ethics committee.

\section{Threat}

Threat perceptions toward the water issue were measured via participants being asked to rate their agreement of seven items on a five-point Likert Scale. Questions such as, "I am more concerned regarding Townsville's water supply than I was six months ago" were used to measure participant's threat perception. An average was taken of all scores to give one threat perception score for each participant. High scores indicated high threat perception.

\section{Perceived Self-efficacy and Perceived Response-efficacy}

Perceived self- and response-efficacy perceptions were measured by asking participants to rate their agreement of four and two items respectively on a five-point Likert Scale. Questions such as "I have the knowledge to be able to adjust my behaviour to help minimise the water issue in the Townsville region" for perceived self-efficacy, and "I do not think saving water will make a substantial positive difference for the city of Townsville" for perceived response-efficacy were used to measure participant's perceptions. An average was taken of all scores to give one perceived self-efficacy and one perceived response-efficacy score for each participant. High scores indicated higher perceived self-efficacy and response-efficacy.

\section{Water Sustainability Behaviours}

Water sustainability behaviours were assessed by participant's indicating the frequency with which they performed each behaviour. Eighteen behaviours were rated on a five-point Likert Scale. A total score of water sustainability behaviour was given to each participant with scores ranging between eighteen and ninety. High scores indicated high frequency of watersustainability behaviour.

\footnotetext{
2 Qualtrics, Provo, Utah, USA, 2017-2018. https://www.qualtrics.com.
} 


\section{Townsville City Council (TCC) Enforced Behaviours}

Behaviours were also split into the Townsville City Council's (TCC) enforced behaviours for Level 3 water restrictions. Four behaviour questions were added together to give a total TCC behaviour score with a possible range between four and twenty for each participant. High scores indicated higher compliance with TCC restriction behaviours.

\section{Negative Impact}

Negative impact of the lack of water in the region on themselves (the participant), their family, Townsville City, and the environment was also measured using four questions. Participants were asked to rate their perceived negative impact of the water issue on a five-point Likert Scale with high scores indicating more perceived negative impact. An average was taken of all scores to give one perceived negative impact score for each measure (the participant themselves, their family, Townsville City, and the environment).

\section{Responsibility}

Questions also assessed how much perceived responsibility the participant believes that they personally, the community, the Townsville City Council, and the State Government had in securing Townsville's water supply. Participants were asked to rate four questions on a five-point Likert Scale, with higher scores indicating high perceived responsibility. An average was taken of all scores to give one perceived responsibility for each measure (the individual personally, the community, the Townsville City Council, and the State Government).

\section{Behaviour Barriers}

Behaviour barriers to performing sustainability behaviours were also assessed. Participants were asked to rate their agreement of seventeen questions on a five-point Likert Scale. Scores were added together to give each participant a total behaviour barrier score, with scores ranging from seventeen to eighty-five. High scores indicated more behavioural barriers to engaging in water saving behaviours.

\section{Procedure}

A k-means cluster analysis was conducted using the R Studio statistical package "cluster." Kmeans cluster analysis was selected as the method for defining clusters as this analysis allows researchers to select the number of cluster a priori. For this analysis, it is recommended that there be a ratio of 100 participants per variable (perceived threat, perceived self-efficacy, and perceived response-efficacy) being entered into the cluster analysis to be statistically sound (Dolnicar, Grun, and Leisch 2018). Therefore, three clusters were selected given there were over 300 participants in the total sample. The $\mathrm{K}$ means cluster analysis was stopped after ten iterations. The variables were standardised given there was a different number of questions used to assess each variable. After conducting the cluster analysis in $\mathrm{R}$, all remaining descriptive and inferential statistical analyses were performed in SPSS (IBM Corp (2015), Version 23). One-way ANOVA tests were used to examine the differences between groups on the variables of interest, with Bonferroni-adjusted post-hoc comparisons run where necessary. Statistical significance was set at $p<0.05$ for all analyses. 


\section{Results}

Cluster analysis resulted in the formation of three groups based on the three factors of the EPPM (perceived threat, perceived self-efficacy, and perceived response-efficacy). Refer to Table 1 for all means and SDs of all variables of interest for each cluster, as well as the relevant information for all inferential statistics performed.

Table 1. Means and SDs for each Cluster on each Variable

\begin{tabular}{|l|l|l|l|l|l|}
\hline & $\begin{array}{l}\text { luster } 1 \\
(n=117)\end{array}$ & $\begin{array}{l}\text { Cluster } 2 \\
(n=90)\end{array}$ & $\begin{array}{l}\text { Cluster } 3 \\
(n=156)\end{array}$ & F-value \\
\hline \multicolumn{1}{|c|}{ Variable } & \multicolumn{4}{|c|}{$M(S D)$} \\
\hline Threat & $3.00(0.53)$ & $4.30(0.47)$ & $3.85(0.53)$ & $171.38^{* *}$ \\
\hline Perceived self-efficacy & $3.24(0.63)$ & $3.61(0.71)$ & $4.10(0.52)$ & $66.80^{* *}$ \\
\hline Perceived response-efficacy & $2.83(0.86)$ & $1.86(0.73)$ & $3.91(0.66)$ & $224.95^{* *}$ \\
\hline Age & $36.50(16.03)$ & $49.22(12.88)$ & $43.29(15.47)$ & $18.28^{* *}$ \\
\hline Years lived in Townsville & $15.54(11.70)$ & $24.98(18.78)$ & $18.66(14.34)$ & $9.38^{* *}$ \\
\hline Water sustainability behaviour & $47.64(13.88)$ & $51.60(12.97)$ & $60.43(10.85)$ & $37.87^{* *}$ \\
\hline TCC sustainability behaviour & $11.95(5.10)$ & $13.58(4.75)$ & $14.88(4.46)$ & $12.73^{* *}$ \\
\hline Negative impact (Participant) & $2.47(1.03)$ & $3.93(0.97)$ & $3.10(1.00)$ & $54.29^{* *}$ \\
\hline Negative impact (Family and friends) & $2.50(0.93)$ & $3.91(0.92)$ & $3.08(0.95)$ & $58.55^{* *}$ \\
\hline Negative impact (Townsville) & $3.32(0.94)$ & $4.44(0.74)$ & $3.99(0.79)$ & $48.70^{* *}$ \\
\hline Negative impact (Environment) & $3.31(1.15)$ & $4.44(0.75)$ & $4.17(0.83)$ & $44.58^{* *}$ \\
\hline Responsibility (Participant) & $2.36(1.01)$ & $1.89(0.95)$ & $2.66(1.21)$ & $14.23^{* *}$ \\
\hline Responsibility (Community) & $2.67(1.14)$ & $1.95(1.02)$ & $2.86(1.25)$ & $17.72^{* *}$ \\
\hline Responsibility (Local Government) & $3.97(0.85)$ & $4.48(0.68)$ & $4.24(0.82)$ & $10.44^{* *}$ \\
\hline Responsibility (State Government) & $3.96(1.00)$ & $4.64(0.68)$ & $4.29(0.80)$ & $16.99^{* *}$ \\
\hline Behaviour barriers & $48.12(8.92)$ & $54.12(8.62)$ & $42.98(6.56)$ & $57.37^{* *}$ \\
\hline
\end{tabular}

Note: $* *$ p sig at $<0.001$

Source: Pardon, Swinbourne, and McShane

A significant difference for the three EPPM variables (perceived threat, perceived self-efficacy, and perceived response-efficacy) was found between all cluster groups. The greatest difference between means between groups was found for the perceived response-efficacy variable, followed by the perceived threat variable.

A significant difference in age was found between all cluster groups, with Cluster 2 being significantly older than participants in other clusters. A significant difference in the number of years lived in Townsville between the clusters was also found, with participants from Cluster 2 reporting as living in Townsville for a significantly shorter amount of time, than participants in Cluster $1(p<0.01)$, as well as Cluster $3(p=.008)$.

In regard to behaviour, a significant difference was found between all cluster groups, with Cluster 3 performing significantly more total water sustainability behaviour than participants in Cluster 1 and 2 (all p-values <0.05). For TCC recommended behaviour, again Cluster 3 
performed the most behaviour. Post hoc analysis showed that Cluster 1 performed significantly less behaviours than Cluster $2(p=0.05)$, and Cluster $3(p<0.01)$.

Significant differences between the three clusters regarding the perceived negative impact of the water issue on the participant, the participant's family and friends, Townsville City and the environment were also found. In each case, participants in Cluster 2 indicated significantly higher perceptions of negative impact than participants in the other clusters (all p-values $<0.05$ ), except between Cluster 2 and Cluster 3 in the negatively impacting the environment variable $(p=.087)$.

A significant difference in perceived responsibility of the water issue belonging to the participant, the community, the local Council and the State Government based on the three clusters was also found. Participants in Cluster 2 indicated that the participant and the community had a significantly lower level of responsibility for the water issue compared to participants in Cluster 1 and 3 (all p-values $<0.05$ ). In contrast, participants in Cluster 2 had significantly higher perceptions of responsibility belonging to the Local Government than participants in Cluster 1 $(p<0.01)$, and significantly higher perceptions of responsibility belonging to the State Government than participants in Clusters 1 and 3 (all $p$-values $<0.05$ )

A significant difference in the total behaviour barrier scores between the three clusters was found, with participants in Cluster 2 reporting significantly more barriers to the performance of water sustainability behaviours than participants in Clusters 1 and 3 (all p-values <0.01). Participants in Cluster 1 also reported significantly more barriers to water sustainability behaviours than participants in Cluster $3(p<0.01)$.

\section{Discussion}

Water sustainability, not only for the city of Townsville but for Australia, is an issue which will continually warrant updated strategies to aid in the preservation of this natural resource. Ideally, making a connection between an individual's threat and efficacy perceptions that would lead to attitudinal and ultimately behavioural changes within communities under environmental threat is of great importance. This study sought to identify and explore this premise, with the main aim of the research to develop clusters of individuals and explore group standings of the EPPM variables within the Townsville community. Specifically, the study explored how individuals perceived the water issue in the Townsville region in terms of perceived threat, perceived selfefficacy and perceived response-efficacy. The EPPM provided a focus on the factors (perceived threat, perceived self- and response-efficacy) that are able to predict individual behaviour and therefore inform researchers about the specific and grouped perceptions the Townsville community held on such a contentious issue in order to inform future environmental threat communications.

Results indicate that behavioural compliance with local water restrictions, as well as general water sustainability behaviour levels were significantly different between all cluster groups. The large variation in perceived response-efficacy between the groups may also demonstrate that if individuals perceive their behaviour is effective, they are more likely to engage in positive behavioural responses. This is evident with Cluster 3 having the highest response-efficacy score and also the highest levels of behaviour compliance. The same association is also found with the perceived threat variable, with Cluster 1 reporting the lowest threat perception and also the lowest level of behaviour compliance. Following the EPPM hypotheses, a low threat perception comes with little to no perceived efficacy, therefore indicating minimal behavioural compliance. The results therefore provide support for the relationship between the EPPM variables and behaviour in the environmental context. That is the relationship between perceived threat, perceived efficacy and behaviour, as predicted by the EPPM, is evident within the sample.

The second aim of the study was to explore the defining characteristics of each cluster. Below is a description of each cluster. This includes the EPPM predictions, demographic information and any other variables of interest to each cluster group. 
Cluster 1 indicated that they had a low perceived threat and perceived self-efficacy perception and a medium perceived response-efficacy perception, compared to the other clusters. Cluster 1 also performed the least amount of water saving behaviours, including Townsville City Council restriction enforced behaviours, of all groups. Cluster 1 indicated that the water supply issue was least likely to negatively impact themselves, friends and family, Townsville and the environment. Fifty-six percent of Cluster 1 indicated they were homeowners. This group was termed the "unconcerned cluster" as this is the youngest group on average and also lived in the Townsville region for (on average) the shortest amount of time of all groups.

According to the EPPM (Witte 1992) a low threat perception is a deterrent of behaviour. Cluster 1, although having low and moderate perceived self- and response-efficacy perceptions, performed the least amount of water sustainability behaviour, which is hypothesised to be a result of a low threat perception. Therefore, participants are not engaging in the first stage of the behavioural process, according to the EPPM (Witte 1992). This may be a result of the participants living the shortest amount of time in the region and therefore not being as attached to the community or effected/impacted by the potential threat compared to those with an assumed greater attachment to Townsville, such as Cluster 2.

Cluster 2 indicated that they had a high threat perception, a medium perceived self-efficacy perception and a low perceived response-efficacy perception compared to the other clusters. This group was mid-range in terms of behavioural compliance but reported the most barriers to engaging in water sustainability behaviours, which may in turn be contributing to their high threat perception. Cluster 2 also had the strongest beliefs that the Local and State Governments were the most responsible for securing the water supply for the community. This may be a result of the large difference between perceived self- and response-efficacy perceptions within this cluster as well as the largest amount of reported perceived barriers compared to other clusters. Cluster 2 indicated that the water supply issue was most likely to negatively impact themselves, friends and family, Townsville and the environment. Eighty-eight percent of Cluster 2 also indicated they were homeowners. This group has been termed the "angry externalisers" as they are the group who appear to place blame externally to themselves.

It could be assumed that this cluster is engaging in the fear control response, as predicted by the EPPM (Witte 1992). More exploration into the specific behaviours that this cluster is engaging in would need to be conducted to confirm this. Cluster 2, although having a high threat perception and engaging in a mid-range amount of sustainability behaviour, may engage in a maladaptive response as it may be useful for the individual to be able to function on a daily basis. Exhibiting a fear control response and performing defensive avoidance responses to minimise the threat perception may reduce fear in an individual (Witte 1994). Similarly, this interaction between variables could also be related to the outcomes of the inverted U-curve of behaviour (Janis 1967, Janis and Feshbach 1953). This theory hypothesises that when the threat perception is too high, this has detrimental effects on behaviour. Cluster 2's large threat perception may be affecting the cluster's ability to perform the necessary behaviour to mitigate the threat. Cluster 2 , being the group that had lived the longest in the region, as well as the majority being homeowners, could also have a high attachment to Townsville and their homes, therefore also contributing to their high threat perception.

Cluster 3 indicated that they had a medium threat perception and high perceived self- and response-efficacy perceptions. Cluster 3 performed the most amount of water saving behaviour of all groups. This group also performed the highest number of Townsville City Council restriction enforced behaviours. Cluster 3 reported the least number of behavioural barriers, which is supported by their high perceived efficacy perceptions. This group rated the highest in terms of blaming themselves and the community as responsible for securing Townsville's water supply and reported the lowest number of behavioural barriers. Seventy-one percent of Cluster 3 indicated they were homeowners. This group was termed the "proactive cluster" due to their apparent positive behaviours. 
Cluster 3 appeared to be engaging in the danger control response of the EPPM. Their moderate threat perception, coupled with high perceived self- and response-efficacy perceptions, according to EPPM predictions, is hypothesised to lead to greater amounts of behaviour (Witte 1992). This is evident given Cluster 3 have performed the most water sustainability behaviours of all clusters. Cluster 3 also have the highest assumed responsibility for securing the water supply which could be the reason for the elevated efficacy perceptions.

Future research could focus on the construction of water sustainability messages based on the constructs of the EPPM and the exploratory analyses of each cluster illustrated above. For example, Cluster 2 would require a message that maintains their threat perception and increases both perceived self- and response-efficacy perceptions, specifically response-efficacy. The message would need to include information that clearly demonstrates the relationship between water sustainability behaviour and its positive effect in terms of benefitting the individual, the community, the town and the environment. Given this group rated the issue as most negatively affecting these factors, this would be appropriate to include to increase perceived responseefficacy. Cluster 2 also indicated that State and Local Governments were most responsible for securing Townsville's water supply. Therefore information educating the participants about how beneficial their own or the communities role in water sustainability is would also be recommended. This ideally would also decrease this cluster's behavioural barriers perceptions.

Future research could also focus on whether exposure to these tailored messages increases sustainable attitudes and ultimately behaviour, as the EPPM predicts, and provide more support to the mixed EPPM and environmental behaviour literature. The current study presents the foundations to be able to construct said messages.

It also appears that perceived threat and perceived response-efficacy could be the biggest drivers of behaviour for this population. This may also be evident in other communities under environmental threat. A more in-depth evaluation of the threat construct, for environmental threats specifically, would be worth exploring to further understand group behaviour and aid in threat message construction. Additionally, the application of this approach in other environment contexts or other regions under environmental threat would also be recommended.

\section{Limitations}

The main limitation of this work is the self-reported nature of behaviour. The water issue within the Townsville region could be considered a sensitive topic, with local government enforced behaviour that results in monetary penalties for non-compliance. It would be reasonable to assume that participants in the study would have biased responding in terms of their water sustainability behaviour compliance because of these factors. As the issue is also politically sensitive, it could also be assumed that certain community groups or individuals may have responded in order to push an 'agenda'. A large and diverse community sample was recruited to counteract this effect. Although every effort should be made to obtain more objective measures of water sustainability behaviour, a laboratory setting for this study would not have been appropriate.

The second limitation of this study concerns the design of the questionnaire. More specifically, that of the questions relating to the three variables used to create the cluster groups (perceived threat, perceived self-efficacy and perceived response-efficacy). Standardisation had to occur given there was a different amount of questions used to access each of the three variables. In future, efforts will be made to increase internal validity.

\section{Conclusion}

The current study contributed to the growing literature regarding the use of the EPPM in the environmental context. It was also successful in demonstrating the use of the EPPM variables in demonstrating the different grouped perceptions within a community. The sub-groups within the 
Townsville community described in this study made it evident that individuals' perceptions of an environmental threat have an impact on their environmental behaviours. This research demonstrates the EPPM's vast application and allows researchers to understand and explore the threat and efficacy perceptions of a population under environmental threat. As the use of fear appeals in the environmental context seems likely in the future, being able to construct such appeals, to a segmented audience, based on a theoretical foundation is hypothesised to increase success in terms of behaviour change. While the 'one size fits all approach' appears to still be the current approach to environmental threat communication, this research lays the foundations for a new strategy for distributing environmental information to at risk populations. With climate change continually bringing adverse change to the environment all over the world, interest in and the development of new and improved messaging to successfully communicate such threats is imperative.

\section{REFERENCES}

Beattie, G., L. Sale, and L. McGuire. 2011. “An Inconvenient Truth? Can a Film Really Affect Psychological Mood and Our Explicit Attitudes towards Climate Change?" Journal of the International Association for Semiotic Studies 187 (1): 105-25. https://doi.org/10.1515/semi.2011.066.

Campo, Shelly, Natoshia M. Askelson, Knute D. Carter, and Mary Losch. 2012. "Segmenting Audiences and Tailoring Messages:Using the Extended Parallel Process Model and Cluster Analysis to Improve Health Campaigns.” Social Marketing Quarterly 18 (2): 98-111. https://doi.org/10.1177/1524500412450490.

Dolnicar, Sara, Bettina Grun, and Friedrich Leisch. 2018. Market Segmentation Analysis: Understanding It, Doing It, and Making It Useful. Singapore: Springer.

Gilg, A., and S. Barr. 2006. "Behavioural Attitudes towards Water Saving? Evidence from a Study of Environmental Actions." Ecological Economics 57 (3): 400-14. https://doi.org/10.1016/j.ecolecon.2005.04.010.

Hart, P. S., and L. Feldman. 2014. "Threat without Efficacy? Climate Change on U.S. Network News." Science $\quad$ Communication $36 \quad$ (3): $325-51$. https://doi.org/10.1177/1075547013520239.

Hine, D. W., J. P. Reser, M. Morrison, W. J. Phillips, P. Nunn, and R. Cooksey. 2014. "Audience Segmentation snd Climate Change Communication: Conceptual snd Methodological Considerations." WIREs Climate Change 5 (4): 441-59. https://doi.org/10.1002/wcc.279.

IBM Corp. Released 2015. IBM SPSS Statistics for Windows, Version 23.0. Armonk, NY: IBM Corp.

Janis, I. L. 1967. "Effects of Fear Arousal on Attitude Change: Recent Developments in Theory and Experimental Research1." In Advances in Experimental Social Psychology, edited by Leonard Berkowitz, 166-224. Cambridge, MA: Academic Press.

Janis, I. L., and S. Feshbach. 1953. "Effects of Fear-arousing Communications." The Journal of Abnormal and Social Psychology 48 (1): 78-92. https://doi.org/10.1037/h0060732.

Leventhal, Howard. 1970. "Findings and Theory in the Study of Fear Communications." In Advances in Experimental Social Psychology, edited by Berkowitz Leonard, 119-86. Cambridge, MA: Academic Press.

Li, S. S. 2014. "Fear Appeals and College Students' Attitudes and Behavioral Intentions toward Global Warming." The Journal of Environmental Education 45 (4): 243-57. https://doi.org/10.1080/00958964.2014.930399.

Lorenzoni, Irene, Mavis Jones, and John R. Turnpenny. 2007. "Climate Change, Human Genetics, and Post-Normality in the UK." Futures 39 (1): 65-82. https://doi.org/10.1016/j.futures.2006.03.005. 
Maibach, E. W., A. Leiserowitz, C. Roser-Renouf, and C. K. Mertz. 2011. "Identifying Likeminded Audiences for Global Warming Public Engagment Campaigns: An Audience Segmentation Analysis and Tool Development." PLoS ONE 6 (3): 1-10. https://doi.org/10.1371/journal.pone.0017571.

Moser, S. C., and L. Dilling. 2004. "Making Climate Hot." Environment 46 (10): 32-46. https://doi.org/10.1080/00139150409605820.

O’Neill, Saffron, and Sophie Nicholson-Cole. 2009. ““Fear Won't Do It”: Promoting Positive Engagement with Climate Change through Visual and Iconic Representations." Science Communication 30 (3): 355-79. https://doi.org/10.1177/1075547008329201.

Perrault, E. K., and S. K Clark. 2018. "Sustainability Attitudes and Behavioral Motivations of College Students: Testing the Extended Parallel Process Model." International Journal of Sustainability in Higher Education 19 (1): 32-47. https://doi.org/10.1108/IJSHE-092016-0175.

Randolf, B., and P. Troy. 2008. "Attitudes to Conservation and Water Consumption." Environmental Science \& Policy $11 \quad$ (5): $441-55$. https://doi.org/10.1016/j.envsci.2008.03.003.

Rimal, Rajiv N., J. Brown, Glory Mkandawire, Lisa Folda, Kirsten Böse, and Alisha H. Creel. 2009. "Audience Segmentation as a Social-Marketing Tool in Health Promotion: Use of the Risk Perception Attitude Framework in HIV Prevention in Malawi." American Journal of Public Health 99 (12): 2224-29. https://doi.org/10.2105/AJPH.2008.155234.

Rogers, Ronald W. 1975. "A Protection Motivation Theory of Fear Appeals and Attitude Change." The Journal of Psychology $91 \quad$ (1): 93-114. https://doi.org/10.1080/00223980.1975.9915803.

1983. "Cognitive and Physiological Processes in Fear Appeals and Attitude Change: A Revised Theory of Protection Motivation." In Social Psychophysiology: A Sourcebook, edited by J. T. Cacioppo and R. E. Petty, 153-76. New York: Guilford Press.

Ruiter, Robert A. C., Charles Abraham, and Gerjo Kok. 2001. "Scary Warnings and Rational Precautions: A Review of the Psychology of Fear Appeals." Psychology \& Health 16 (6): 613-30. https://doi.org/10.1080/08870440108405863.

Witte, K. 1992. "Putting the Fear Back into Fear Appeals: The Extended Parallel Process Model." Communication Monographs $59 \quad$ (4): $\quad 329-49$. https://doi.org/10.1080/03637759209376276.

1994. "Fear Control and Danger Control: A Test of the Extended Parallel Process Model (EPPM)." Communication $\quad$ Monographs $61 \quad$ (2): $113-34$. https://doi.org/10.1080/03637759409376328.

Xue, Wen, Donald W. Hine, Anthony D. G. Marks, Wendy J. Phillips, Patrick Nunn, and Shouying Zhao. 2016. "Combining Threat and Efficacy Messaging to Increase Public Engagement with Climate Change in Beijing, China." Climatic Change 137 (1): 43-55. https://doi.org/10.1007/s10584-016-1678-1.

\section{ABOUT THE AUTHORS}

Madelyn Pardon: PhD Candidate, Division of Tropical Health and Medicine, James Cook University, Townsville, Queensland, Australia

Dr. Anne Swinbourne: Senior Lecturer, Division of Tropical Health and Medicine, James Cook University, Townsville, Queensland, Australia

Dr. Connar McShane: Senior Lecturer, Division of Tropical Health and Medicine, James Cook University, Townsville, Queensland, Australia 